\title{
Are X-linked cutis laxa and Menkes disease allelic?
}

Sir - X-linked cutis laxa, or the occipital horn syndrome, is a connective tissue disorder characterized by hyperelastic and bruisable skin, varicosities, hernias, bladder diverticula and skeletal abnormalities, including long bone and occipital exostoses ${ }^{1}$. Clinical and biochemical investigations have confirmed X-linkage and revealed a deficiency of the cuproenzyme, lysyl oxidase, in affected males ${ }^{2}$. However, lysyl oxidase is encoded by an autosomal gene ${ }^{3}$, eliminating the possibility that mutations in the lysyl oxidase gene are responsible for the disorder.

It has instead been proposed that $\mathrm{X}$-linked cutis laxa is a primary defect of copper transport and may in fact be allelic to Menkes syndrome ${ }^{4,5}$. Several lines of evidence support this hypothesis. Serum ceruloplasmin and copper concentrations are decreased, and copper concentrations are elevated in cultured skin fibroblasts of patients and heterozygotes ${ }^{4,5}$. These biochemical findings are strikingly similar to those of another disorder of copper metabolism - Menkes disease. The secondary reduction of lysyl oxidase in Menkes disease ${ }^{6}$ is comparable to that seen in X-linked cutis laxa. Furthermore, while the clinical picture of Menkes disease is often dominated by severe neurologic deterioration, some of the connective tissue manifestations appear in both disorders, and cutis laxa patients may show mild-to-moderate central nervous system manifestations. The proposed allelic relationship of the two syndromes is further strengthened by analogy with the alleles of the mottled mouse, which show greater or lesser degrees of connective tissue involvement in addition to differences in severity?

It is now possible to dissect the relationship between these two disorders, as a candidate gene for
Menkes disease is reported in this issue of Nature Genetics ${ }^{8-10}$. This gene encodes a 1,500 amino acid protein with features of a P-type coppertransporting ATPase. The cDNA

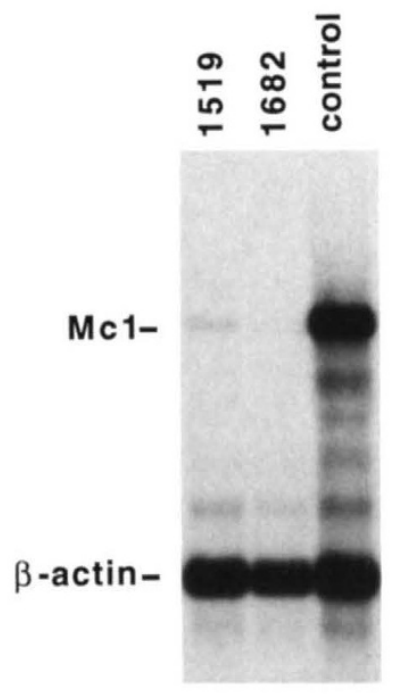

Expression of the copper-transporting ATPase gene (Mc1) in X-linked cutis laxa patients. Northern blots of polyA+RNA, extracted from fibroblast lines of two unrelated males with cutis laxa (1519 and 1682) and an unaffected control individual, were hybridized with a partial coppertransporting ATPase cDNA probe and a b-actin probe as described ${ }^{8,11}$. We gratefully acknowledge the generous gifts of cell lines from Louis J. Elsas, III, Gregory Barsh and Kurt Hirschhorn.

detects an 8.5 kilobase transcript which is absent, markedly reduced, or altered in size in cell lines from many Menkes patients. Using our cDNA probe, designated $\mathrm{Mcl}$ (ref. 8), we asked whether expression of this gene was abnormal in cells from two patients with $\mathrm{X}$-linked cutis laxa. As shown in the figure, expression of $\mathrm{Mcl}$ is markedly reduced in fibroblasts of two unrelated cutis laxa hemizygotes. Hybridization with a $\beta$ - actin probe documented the approximately equivalent levels of RNA in each sample. Southern blot analysis ofDNA from the two patients did not reveal any rearrangements of the $\mathrm{Mcl}$ gene (data not shown).

The present data extend previous observations linking the defects in Xlinked cutis laxa and Menkes disease. The studies suggest that in some patients with X-linked cutis laxa the expression of $M c l$ is reduced, a finding which is indistinguishable from that observed in some Menkes patients. The data therefore suggest a role for the $\mathrm{Mcl}$ gene product in $\mathrm{X}$-linked cutis laxa, but do not explain the divergent phenotypes of this disorder and Menkes disease. Further studies should reveal the relationship between these two disorders.

Barbara Levinson

Jane Gitschier

Department of Medicine

and the Howard Hughes Medical Institute

Christopher Vulpe

Department of Biochemistry

Susan Whitney

Samuel Yang

Seymour Packman

Division of Genetics, Department of Pediatrics University of California,

San Francisco California 94143, USA

References

1. Lazoff, S. et al. Birth Defects Orig. Art. Ser XI(5), 71-74 (1975).

2. Byers, P. et al. New Engl. J. Med, 303,61-65 (1980).

3. Hamalainen, E. et al. Genomics 11, 508-516

4. Kuivaniemi, H. et al. J. clin. Invest. 69, 730-733 (1982).

5. Peltonen, L. et al. Biochemistry 22, 6146-6163 (1983).

6. Royce, P. et al. Blochem. J. 192, 579-586 (1980).

7. Miller, J. X-Linked Traits: A Catalog of Loci in Nonhuman Mammals (Cambridge University Press, 1990).

8. Vulpe, C. et al. Nature Genet.3, 7-13 (1993).

9. Chelly, J. et al. Nature Genet.3, 14-19 (1993).

10. Mercer, J.F.B. et al. Nature Genet.3, 20-25 (1993).

11. Levinson, B. et al. Genomics 7, 1-11 (1990). 